\title{
Mwayila Tshiyembe, Géopolitique de paix en Afrique médiane
}

L'Harmattan, $220 \mathrm{p}$.

\section{Mwanza wa Mwanza}

\section{OpenEdition}

Journals

Édition électronique

URL : http://journals.openedition.org/belgeo/13447

ISSN : 2294-9135

Éditeur :

National Committee of Geography of Belgium, Société Royale Belge de Géographie

Édition imprimée

Date de publication : 31 décembre 2004

Pagination : 497-508

ISSN : 1377-2368

\section{Référence électronique}

Mwanza wa Mwanza, "Mwayila Tshiyembe, Géopolitique de paix en Afrique médiane », Belgeo [En ligne], 4 | 2004, mis en ligne le 15 septembre 2013, consulté le 22 septembre 2020. URL : http:// journals.openedition.org/belgeo/13447

Ce document a été généré automatiquement le 22 septembre 2020.

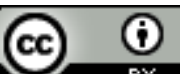

Belgeo est mis à disposition selon les termes de la licence Creative Commons Attribution 4.0 International. 


\section{Mwayila Tshiyembe, Géopolitique de paix en Afrique médiane}

L'Harmattan, 220 p.

Mwanza wa Mwanza

\section{RÉFÉRENCE}

Mwayila Tshiyembe (2003), Géopolitique de paix en Afrique médiane, L'Harmattan, 220 p.

1 Le livre remet la problématique de la paix en Afrique médiane au cœur même de la question de la légitimation de l'État, de représentation politique et de la légitimité du pouvoir. Ces questions constituent la matrice de la conflictualité interne qui ensanglante la région de l'Afrique médiane, et la violence politique en est la variable structurelle. Ce que l'auteur illustre bien à partir de l'analyse du cas de la République démocratique du Congo (RDC), dans les chapitres 2 et 3 de la première partie.

2 L'auteur fait dans la deuxième partie du livre (pp. 99-180) une véritable autopsie des différents Accords de paix signés au Burundi, en République démocratique du Congo (RDC), en Ouganda, en Angola et au Congo Brazzaville pour mettre fin au contexte de conflictualité politique. Si l'auteur relève ici et là quelques avancées dans la prise en compte des réalités locales dans ces processus de recherche de la paix, force est de constater que les termes de ces dispositifs demeurent largement corsetés dans l'illusion de (re)construction de la paix dans le cadre de l'Etat-nation ou encore par l'Etat de droit $^{1}$. Or pour l'auteur le formalisme démocratique et l'ingénierie juridique copiés sur le modèle occidental de l'Etat-nation ne sont pas à même de constituer une réponse à la violence politique structurelle qui sévit en Afrique médiane, comme partout en Afrique noire. Ainsi, il propose dans la troisième partie du livre de rompre avec l'Etat-nation pour créer les conditions de réinvention de l'État multinational ou d'une république multiethnique : par la refondation du pacte républicain, du pacte démocratique et du pacte constitutionnel, d'une part; par le pacte régional de non-agression et de 
coprospérité économique, d'autre part. Une contribution à la renaissance de la l'État en Afrique noire qui mérite d'être diffusée, discutée et affinée.

\section{NOTES}

1. Lire MWANZA WA M., Le processus de (re)construction de l'État au Congo-Kinshasa à l'épreuve des faits : la question du pouvoir local, BCAS, Projet GOA, 2004 (à paraître). 